\title{
Determination of Salmonella in egg shell and egg content in some selected areas of Bangladesh
}

\author{
Akter $\mathrm{S}^{1}$, Ferdowshi $\mathrm{Z}^{3}$, Islam $\mathrm{MN}^{1,2}$, Prodhan MAM${ }^{1}$ and Chowdhury MYE ${ }^{1^{*}}$ \\ ${ }^{1}$ Chittagong Veterinary and Animal Sciences University, Bangladesh ${ }^{2}$ Massey University, New Zealand \\ ${ }^{3}$ Universiy of Science and Technology Chittagong, Bngladesh
}

[Received: July 02, 2015; Accepted: December 03, 2015]

\begin{abstract}
Salmonellosis is one of the most common and widely distributed food-borne diseases. It constitutes a major public health burden and represents a significant cost in many countries. Salmonella are known for its wide range host and can cause clinical diseases in some hosts while in others, can be asymptomatic. Poultry and eggs are considered as major sources for different pathogenic Salmonella serotypes. Eggs produced locally under the small scale layer farm may present a hazard to consumers which may increase the spread of Salmonella in the environment. To investigate the occurrence of Salmonella, a total of 72 samples were taken from 6 poultry farm in some selected areas of Bangladesh. Sampling program was executed between October and December, 2013 and samples were tested using standard laboratory methods. Data was collected through direct interview and structured questionnaire. Our study shows that, true prevalence of Salmonella in egg shell and egg contents were $0.093 \%$ and $0.068 \%$ respectively. The highest apparent prevalence in Udayan poultry farm (50\%) and lowest in Liza poultry farm $(16.67 \%)$. The average frequency of egg shell contamination is positively correlated with re-use of egg tray without disinfection. To the best of our knowledge, this is the first investigation on Salmonella spp. in selected local egg production farms in Chittagong. Further detail study is highly recommended.
\end{abstract}

Keywords: Salmonella, small scale layer farm, table egg, food borne diseases, public health.

\section{INTRODUCTION}

Poultry products especially the eggs and egg products plays vital nutritive role in human health specifically for developing country like Bangladesh [1] [2]. Eggs are enriched with protein, minerals, fat and different vitamins like vitamin $\mathrm{B}_{12}{ }^{[3]}$. However, consuming inaccurately treated eggs and egg products can causes food borne diseases like salmonellosis ${ }^{[4]}$. Salmonella is a major food-borne pathogen distributed worldwide and contaminated poultry products ${ }^{[5]}$. In fact, Salmonellosis is considered as major public health burden in developing countries and important food borne pathogen in developed countries ${ }^{[6][7]}$. Broad range of Salmonella like Salmonella choleraesuis, $S$. enterica, $S$ bongori, S. typhi, $S$ paratyphi and $S$. typhimurium causes gastrointestinal (GIT) and typhoid fever. Among them, S. enterica subspecies enteric is responsible for more than $99 \%$ infection in man and animal ${ }^{[8]}$. Most of the infections of Salmonella are zoonotic in nature except $S$. typhi and $S$. paratyphi. The non typhoidial salmonellosis has been increased dramatically in past 10 years with predominant serotypes of $S$. enteric serotype enteritidis and S. typhimurium ${ }^{[9]}$.

Salmonella spp. contaminating food and food products can causes Salmonellosis. Animal originated foods like poultry, poultry products and raw eggs are often contaminated by different Salmonella spp. However, other sources of exposure include water, vegetables, fruits, pet and domestic animal handling and person-to-person when hand- mouth contact occurs without proper personal hygiene. Human cases of salmonellosis caused by $S$. enteritidis increased recently due to ingestion of poultry products specifically eggs ${ }^{[10]}$. Additionally, presence of Salmonella spp. in egg shell also possesses a considerable public health hazards and economic losses in poultry industry. Contamination of egg by Salmonella spp. may cause at any stage of production like collection, transportation or marketing through vertical or horizontal transmission. Importantly, reusable egg tray is a potential source for contaminating egg shell by salmonella in developing country like Bangladesh. Small scale layer farms are the major source of eggs in Bangladesh. The egg consumption is considerably increased in Bangladesh in past two decade due to promotion of egg as an ideal food by GO and NGO. So it could be acted as a potential vehicle of salmonella transmission in human but it is unlikely to develop surveillance program in Bangladesh like other develop country. Concern authorities are not aware of salmonella at farm level due to constrain of resource and facilities. The actual data on prevalence of salmonellosis in eggs and egg products is poorly documented that prone to zoonotic threat. In addition, small scale commercial farm is predominant in Bangladesh with minimum biosecurity practices unlike other large scale commercial production system; enhance the chance of infection to the birds. The data on prevalence and rate of infection in eggs and egg products in Bangladesh is limited. Furthermore, in Bangladesh, there are no directives to control the process of egg production ${ }^{[11]}$ or limited study to evaluate the quality 
of eggs in Bangladesh. This investigative work is proposed to address this issue and was focus on table egg produced in local farms to determine the apparent and true prevalence of egg contamination by Salmonella spp. with the associated factors.

\section{MATERIALS AND METHODS}

\section{Study design and data collection}

Small scale commercial layer farm $(n=6)$ of Chittagong $(n=3)$ and Noakhali $(n=3)$ were selected purposively for the study. The Jafar Poultry Farm (farm 1), Hoque Poultry Farm (farm 2) and Kachwya Poultry Farm (farm 3) is located in Moddhomchorkakra, Charparbotipur and Bagtara village of Companygonj upazilla respectively. The Udayan Poultry Farm (farm 4), Islam Poultry Farm (farm 5) and Liza Poultry Farm (farm 6) is located in Satkaniya, potiya and chandanish of Chittagong districts. The landscape characteristics of this study were both high and lowland where farming is major way of livelihood. A cross sectional study was conducted in selected farms for the investigation of and 6 having Isa brown strain while 3, 4 and 5 were rearing Hisex brown strain of layer bird. The study was conducted between October and December 2013. A structured record keeping sheet was developed, validated and used to collect the necessary information. The questionnaire contained closed, semi closed and open ended question. The questionnaire was grouped on: 1) basic information related to farm identity, farm composition and bird demography, 2) farm management system related to biosecurity level of farm and 3) egg collection, preservation and marketing procedure. All information was collected by face to face interview to the farm owner, manager or attendance as well as by physical examination.

\section{Source population and sample collection:}

Only egg laying flocks of each farm were used to develop the sampling frame where smallest unit consist of 2000 birds. Initially, 12 fresh eggs were collected from the selected farms and transported to microbiology laboratory at Chittagong Veterinary and Animal Sciences University (CVASU). Obtained samples were transferred carefully with a layer of sterile cotton for avoiding the breakage of egg. Each

Table 1: Result of sample culture on XLD, SS agar and TSI for Salmonella isolation and identification. Farms egg samples $\quad$ Positive samples in different media Microscopic features

Egg shell Egg inner mass

\begin{tabular}{cccccccll} 
& & XLD & SS & TSI & XLD & SS & TSI & \\
\hline F1 & 12 & 8 & 6 & 6 & 4 & 6 & 4 & Gram-negative, \\
F2 & 12 & 0 & 4 & 2 & 2 & 4 & 2 & pink colored, \\
F3 & 12 & 4 & 6 & 4 & 6 & 6 & 6 & small rod \\
F4 & 12 & 8 & 6 & 6 & 6 & 2 & 2 & \\
F5 & 12 & 6 & 8 & 6 & 4 & 6 & 4 & \\
F6 & 12 & 4 & 4 & 4 & 4 & 2 & 4 & \\
\cline { 1 - 5 } Total & 72 & 30 & 34 & 28 & 26 & 26 & 22 & \\
\hline
\end{tabular}

F1= Jafar poultry, F2= Hoque poultry, F3= Kachuyapoultry, F4= Udayan poultry, F5 = Islam poultry and F6 = Liza poultry

On SS agar salmonella colonies were blackish and in XLD agar, the colonies appeared as black centered because of $\mathrm{H}_{2} \mathrm{~S}$ production (Figure 1).

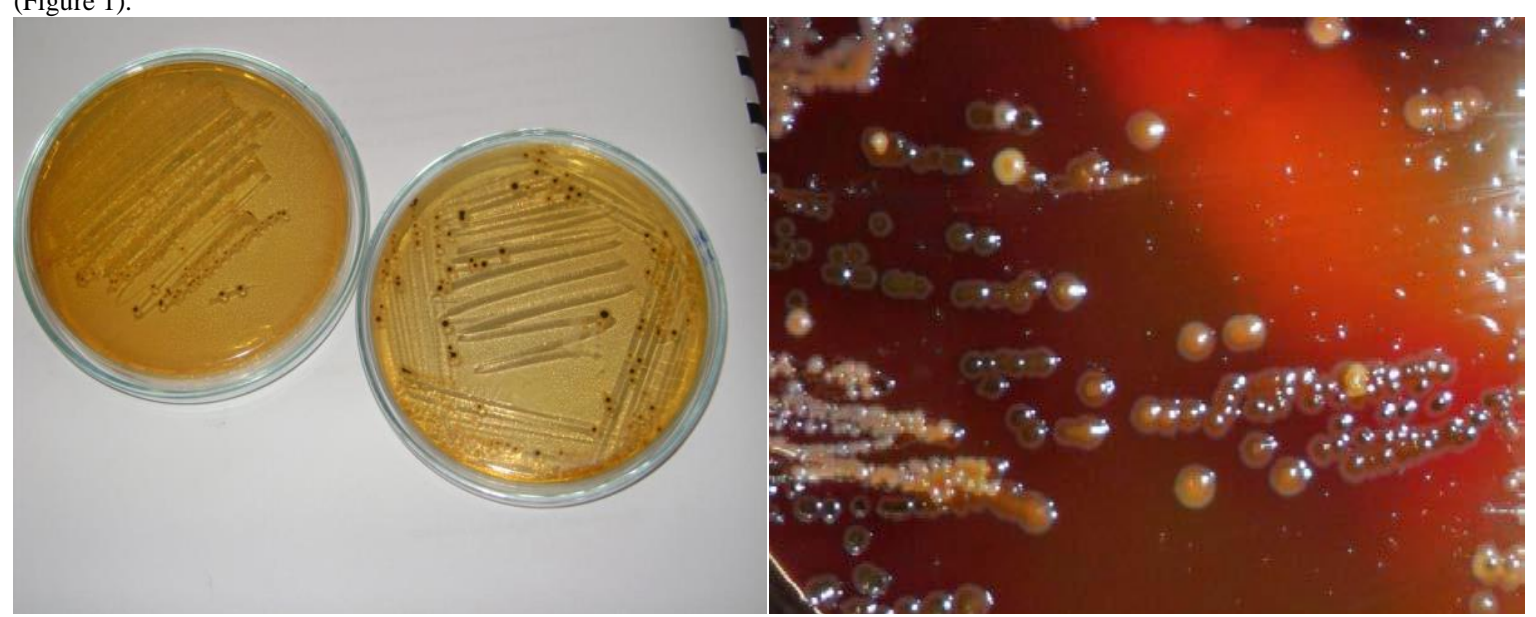

Figure 1. Black centered colony in XLD agar suspected to Salmonella spp.

Salmonella spp. and associated factors for its prevalence in table eggs of small scale layer farms. The studied farm 1, 2, 3, have 4000, 2000 and 2500 birds of Noakhali and farm 4, 5, 6 have 1800, 7000 and 4000 birds of Chittagong. The studied farm 1, 2 egg was given a unique identification number according to the farm identity and strain of the farm. The samples were preserved in $4^{\circ} \mathrm{C}$ until processing.

Media and inoculum 
Nutrient agar (Oxoid Ltd., $\mathrm{P}^{\mathrm{H}}$ : 6.2 \pm 0.0 ) was used as primary enrichment media. The Xylose Lysine Deoxycholate (XLD) agar (Oxoid Ltd., $\mathrm{P}^{\mathrm{H}} 7.4 \pm 0.2$ ), Salmonella-Shigella (SS) agar (Merck, $\mathrm{P}^{\mathrm{H}}: 6.9 \pm 0.2$ ) and TSI agar (Oxoid Ltd., $\mathrm{P}^{\mathrm{H}}: 7.2 \pm 0.2$ ) were also used as selective media for the isolation of Salmonella spp. All the samples were subjected to the laboratory evaluation. The swabbing techniques were used to detect the Salmonella spp. in egg shell. The inner masses were inoculated in media for the detection of salmonella in egg inner mass as described previously ${ }^{[12]}$. For the preparation of microscope at $100 \times$ magnification for bacterial characterization. For further confirmation, the colonies were subjected to the biochemical analysis by TSI slant by stabbing the butt down to the bottom, and then streaked over the surface of the slant. The TSI slant was incubated overnight at temperature of $37^{\circ} \mathrm{C}$. The positive results for salmonella were detected based on the properties.

Data analysis

Data obtained was imported to the Microsoft Office Excel-2007 and transferred to the software STATA/IC-11 for analysis. Descriptive statistics and associated factors were correlated with high

Table 2. True and apparent prevalence of Salmonella spp in egg samples

\begin{tabular}{|c|c|c|c|c|c|c|c|c|c|}
\hline $\begin{array}{l}\text { Farm } \\
\mathrm{s}\end{array}$ & $\begin{array}{l}\text { Total } \\
\text { populatio } \\
\mathrm{n}\end{array}$ & $\begin{array}{l}\text { Average } \\
\text { egg } \\
\text { productio } \\
\text { n/ } \\
\text { day }\end{array}$ & $\begin{array}{l}\text { Sample } \\
\text { s } \\
\text { collecte } \\
\text { d }\end{array}$ & $\begin{array}{l}\text { AP (ES } \\
\%)\end{array}$ & $\begin{array}{l}\text { AP } \\
(\mathrm{EC}) \%\end{array}$ & $\begin{array}{l}\mathrm{TP} \\
(\mathrm{ES}) \%\end{array}$ & $\begin{array}{l}\mathrm{TP} \\
(\mathrm{EC}) \%\end{array}$ & $\begin{array}{l}\text { Average } \\
\text { TP } \\
(\mathrm{ES}) \%\end{array}$ & $\begin{array}{l}\text { Averag } \\
\mathrm{e} \\
\mathrm{TP}(\mathrm{EC}) \\
\%\end{array}$ \\
\hline F1 & 3811 & 3650 & 12 & $50 \%$ & $33.33 \%$ & $0.079 \%$ & $0.052 \%$ & \multirow{6}{*}{$0.093 \%$} & \multirow{6}{*}{$0.068 \%$} \\
\hline $\mathrm{F} 2$ & 4700 & 4500 & 12 & $16.66 \%$ & $16.66 \%$ & $0.02 \%$ & $0.021 \%$ & & \\
\hline F3 & 2382 & 2000 & 12 & $33.33 \%$ & $50 \%$ & $0.08 \%$ & $0.126 \%$ & & \\
\hline $\mathrm{F} 4$ & 1846 & 1750 & 12 & $50 \%$ & $16.66 \%$ & $0.16 \%$ & $0.054 \%$ & & \\
\hline F5 & 1603 & 1500 & 12 & $50 \%$ & $33.33 \%$ & $0.19 \%$ & $0.125 \%$ & & \\
\hline F6 & 6635 & 5800 & 12 & $33.33 \%$ & $33.33 \%$ & $0.03 \%$ & $0.03 \%$ & & \\
\hline
\end{tabular}

$\mathrm{AP}=$ Apparent prevalence, $\mathrm{TP}=$ True prevalence, $\mathrm{ES}=$ Egg shell, EC=Egg content, $\mathrm{F} 1=$ Jafar poultry, F2= Hoque poultry, F3= Kachuya poultry, F4= Udayan poultry, F5 = Islam poultry and F6 = Liza poultry

inoculums of egg shell surface, a sterile cotton swab wetted in sterilized normal saline solution (NSS) was used for surface swabbing and it was re-immersed into the same tube having $10 \mathrm{ml}$ NSS. The surfaces of each of the egg were primarily disinfected with $70 \%$ ethanol and then the eggs were broken to collect the inner content swab. Finally, the content thoroughly mixed for approximately 1 minute and centrifuged for preparation of inoculum of inner content.

Isolation and identification of Salmonella spp. frequency of egg contamination within farm level through descriptive statistics.

\section{RESULTS}

Confirmation of Salmonella spp. by cultural and biochemical characteristics

Among farms, the highest egg shell contamination by salmonella recorded in farm 1 and $4(n=8)$ and none from farm 2 in XLD. Similarly, in the case of inner content of egg, farm 3 and $4(n=3)$ showed highest

Table: 3 Salmonella positive $\%$ within different strain

\begin{tabular}{lllll}
\hline Strain & $\begin{array}{l}\text { Salmonella positive } \\
(\text { Egg shell) }\end{array}$ & $p$-value & $\begin{array}{l}\text { Salmonella positive } \\
(\text { Egg content) }\end{array}$ & $p$-value \\
\hline Isa brown & $66.67 \%$ & $0.273^{*}$ & $66.67 \%$ & $0.406^{*}$ \\
Hisex brown & $100 \%$ & & $33.33 \%$ & \\
\hline$* N S=$ non-signficant & & &
\end{tabular}

$1 \mathrm{ml}$ of prepared inoculum from egg shell and egg inner mass was inoculated in screw cap test tube containing nutrient broth and incubated for 24 hours (h) at $37^{\circ} \mathrm{C}$. After incubation a loopful of culture was streaked on both XLD and SS agar and incubated at $37^{\circ} \mathrm{C}$ for $24 \mathrm{~h}$. The colonies with black center in XLD and blackish growth in SS were considered as presumptive Salmonella spp. Suspected colonies were taken over a slide and allowed it to air dry followed by fixation in light flame. Gram's staining was performed as per procedures described by Merchant and Packer (1969) ${ }^{[13]}$ and observed under number of positive and lowest from farm 2. In case of SS agar highest egg shell contamination was recorded in farm $5(n=8)$ and lowest $(n=2)$ in farm 2 and 6 . In case of inner content, farm 1,3 and 5 showing higher $(n=6)$ than others. The positive samples from XLD and SS agar were further analyzed in TSI slant for final confirmation. Among all positive cases of 6 studied farm, a total number of 28 eggs shell and $22(n=72)$ egg inner content found positive to the Salmonella spp. in TSI slant media (Table 1). 


\section{Determination of apparent and true prevalence of Salmonella spp}

Individual and overall salmonella positive percentages in egg of studied farm were also determined on the basis of biochemical test. The overall apparent prevalence of salmonella in table egg collected from study area was $38.8 \%$ in egg shell and $30.5 \%$ in egg inner content while in individual farm level, highest prevalence was $50 \%$ in Jafar, Islam and Udayan Poultry Farm. On the contrary, lowest prevalence was observed in Hoque Poultry of $16.66 \%$. Others, $33.3 \%$ prevalence was observed in both Liza and Kachuya Poultry Farm.

In the case of strain variation, among the positive samples we found that, Hisex brown showed $100 \%$ in egg shell and $33.33 \%$ in egg content were products, including eggs, have been consistently implicated in sporadic cases and outbreaks of human salmonellosis ${ }^{[16]}$. Several studies referring the salmonella contamination in both inner mass and outer shell of eggs responsible for human infection [17]. The aim of this study was to determine the presence of Salmonella spp. in eggs in selected local farms where the true and apparent prevalence of salmonella in table egg from both egg shell and inner contents were determined. The true prevalence of egg shell contamination by salmonella was $0.093 \%$ and egg inner content was $0.068 \%$. The incidence levels of $S$. enteritidis in egg shell reported earlier were variable. In Spain, [18] around 0.8 to $1 \%$ salmonella contaminated eggs were reported while in United Kingdom, prevalence was from zero ${ }^{[19,20]}$ to

Table: 4 Associated factor for infection of Salmonella spp. in farm level

\begin{tabular}{|c|c|c|c|c|c|c|}
\hline \multicolumn{7}{|l|}{ Farm management factor } \\
\hline Traits & F1 & $\bar{F} 2$ & F3 & $\mathrm{F} 4$ & F5 & F6 \\
\hline Pullets reared on floor & $\mathrm{Y}$ & $\mathrm{N}$ & $\mathrm{Y}$ & $\mathrm{N}$ & $\mathrm{N}$ & $\mathrm{N}$ \\
\hline Feed contains animal products & $\mathrm{Y}$ & $\mathrm{Y}$ & Y & $\mathrm{Y}$ & Y & Y \\
\hline Water chlorinated & $\mathrm{N}$ & $\mathrm{Y}$ & $\mathrm{N}$ & $\mathrm{N}$ & $\mathrm{N}$ & $\mathrm{Y}$ \\
\hline Visitors allowed (no business) & $\mathrm{Y}$ & $\mathrm{N}$ & $\mathrm{N}$ & $\mathrm{Y}$ & $\mathrm{N}$ & $\mathrm{N}$ \\
\hline Proper Manure handling & $\mathrm{N}$ & $\mathrm{Y}$ & $\mathrm{N}$ & $\mathrm{Y}$ & $\mathrm{Y}$ & $\mathrm{Y}$ \\
\hline \multicolumn{7}{|c|}{ Cleaning and disinfecting between flocks } \\
\hline Cages, walls, ceiling & ST & $\mathrm{Y}$ & $\mathrm{Y}$ & $\mathrm{N}$ & ST & $\mathrm{Y}$ \\
\hline Wash and fumigate & $\mathrm{Y}$ & $\mathrm{Y}$ & $\mathrm{Y}$ & $\mathrm{Y}$ & $\mathrm{Y}$ & $\mathrm{Y}$ \\
\hline \multicolumn{7}{|l|}{ Egg collection and marketing } \\
\hline Reuse of egg trey & $\mathrm{Y}$ & $\mathrm{Y}$ & $\mathrm{Y}$ & $\mathrm{Y}$ & $\mathrm{Y}$ & Y \\
\hline Washing and disinfecting the egg trey & $\mathrm{N}$ & $\mathrm{Y}$ & ST & $\mathrm{N}$ & $\mathrm{Y}$ & $\mathrm{Y}$ \\
\hline Vehicle disinfected & $\mathrm{N}$ & $\mathrm{Y}$ & $\mathrm{N}$ & $\mathrm{ST}$ & $\mathrm{N}$ & ST \\
\hline Storage room disinfection & $\mathrm{N}$ & $\mathrm{Y}$ & $\mathrm{N}$ & $\mathrm{N}$ & $\mathrm{N}$ & $\mathrm{N}$ \\
\hline
\end{tabular}

$\mathrm{F} 1=$ Jafar poultry, F2= Hoque poultry, F3= Kachuya poultry, F4= Udayan poultry, F5 = Islam poultry and

F6 = Liza poultry and $\mathrm{Y}=\mathrm{yes}, \mathrm{N}=\mathrm{No}$ and $\mathrm{ST}=$ Some times

salmonella positive. On the other hand, Isa brown is showing similar percentages of salmonella contamination in both egg shell and inner content of the eggs $(66.67 \%)$. There were no statistically significance among the strain variation (Table 3 ).

Factor associated with the presence of Salmonella spp. in egg shells and egg contents

The table 4 showing that, the overall management system of Liza Poultry farm was better than the other as they follow the strict bio-security measurement. However, the management system of other farm is more or less similar except Islam Poultry which was better than the rest of farms except Liza farm. For collection and transportation of egg, all poultry farms were reusing the tray without disinfection except Liza and Islam Poultry Farm, who were regularly using disinfectant before using the tray. The vehicle of egg transportation was usually used without any disinfection except Liza Poultry Farm.

\section{DISCUSSION}

Egg and egg products is vital human dietary content due to lower cost ${ }^{[14]}$. But improperly handled egg could be source of public health hazard ${ }^{[15]}$. Foods of animal origin, especially poultry and poultry
$2 \%{ }^{[21]}$. The prevalence of salmonella in egg shell and egg content from bulk egg processing plant is also reported $0.5-3.7 \%$ in United States of America [16, 22, and 23]. Recent study in France showed that, prevalence of salmonella in the egg shells was 0.3 $1.05 \%{ }^{[24]}$. The findings of current study are more or less consistent with previously stated studies. However, there are some contrary in India and other country recorded higher prevalence of salmonellosis in market egg content and shell. In Coimbatore of South India found overall 3-7\% Salmonella infection in egg shell and $2-4 \%$ in egg inner content ${ }^{[25]}$. This study is higher than our true prevalence but correspondence to our apparent prevalence. The variation may be due to individual sampling in comparison to pooled survey sampling ${ }^{[26]}$. Other study in Belgium, New Zealand, Australia, and Canada reported a range of $2-13 \%$ salmonella infection in large sampling frame as part of public health surveillance system ${ }^{[26-28]}$. A study on table egg in Dhaka city showed overall $14-17 \%$ inner egg and $18-31 \%$ egg shell contamination with Salmonella Spp. Another study in Khulna city found $8 \%$ eggs were contaminated by Salmonella spp. In which $3 \%$ $S$. typhi and rest of $S$. enterica. The findings is very close to our apparent prevalence in farm level that is 
$30-35 \%$. Our study found higher contamination in egg shell than the inner content by Salmonella spp. Another study in northern part of India reported that lower frequency in egg shell (1-2\%) but higher frequency in egg content (8\%) contamination ${ }^{[17]}$. The collected samples were from retail and wholesale market of that study. Our study was supported by another study done in India, where they reported that, higher incidence on egg shell surface than the internal contents. In our study, true prevalence in individual farm level showed highest in farm 1 of both in egg shell $(0.079 \%)$ and egg inner content $(0.052 \%)$ and lowest $(0.03 \%)$ in farm 6 ranges from $0.23-1.5 \%$. The result is little lower than one study ${ }^{[24]}$ while similar to another ${ }^{[29]}$. In this study, the apparent prevalence showed highest in farm 1 and farm $4(50 \%)$. The apparent prevalence is higher than the study conducted in Pakistan $(35 \%)$ ${ }^{[30]}$, India ${ }^{[17]}(28 \%)$. This variation may be causes due to small sampling strategy of our study or sensitivity of diagnosing tools used for the detection of salmonella ${ }^{[31]}$. Alternatively, it could be higher for the farm level prevalence of salmonellosis in birds. Eggs from known infected flocks of commercial layer farm could be expected to more prevalence of salmonella contamination. The overall prevalence of salmonellosis in commercial layer farm in Bangladesh is ranged from $8-24 \%{ }^{[32]}$. So the current study findings of $33 \%$ are more or less consistent to the farm level infection. The previously reported Salmonellosis in a farm or known infected farm's egg showed higher prevalence in Salmonella contamination $^{[27]}$. Three of our studied farm having salmonella infection during the study period which causes highest level of contamination in inner egg mass. Various study on epidemiological risk factor in egg contamination suggested that regular vaccination could decrease the level of contamination in farm by Salmonella spp. ${ }^{[33,34]}$. Our studied farm 2 and farm 6 were practicing regular vaccination against salmonella. It could be the reason of lower prevalence than other in egg content. Small scale layer farm with low biosecurity measurement in Bangladesh may causing higher incidence of salmonella infection in farm level resulting higher rate of egg contamination ${ }^{[32,35]}$. In this study, low bio secured farm showed higher frequency of egg contamination. The Jafar poultry, where the visitors are allowed and improper handling of manure having highest rate of egg contamination than others. The farmers in the study area used to buy fish meal or other feed ingredients from the local markets where birds and eggs of different farms are also selling. The same vehicles are using for transportation of birds, eggs and feeds between the farms and the markets, and in most cases, these vehicles remain contaminated with faces, and non-disinfected. Different degrees of fecal contaminations of vehicles and frequencies of market visits may have role in higher frequency of salmonella infection in eggs ${ }^{[32]}$. In our study, higher frequency of egg shell contamination shows in farm 1 and farm 4 where same vehicle are using for transportation of feed as well as egg marketing. The farms are not concern about disinfecting there vehicle during transportation of egg in the market. Reuse of egg tray for the collection and transportation of egg in developing countries like Bangladesh have influence in contamination of egg ${ }^{[30]}$. But regular disinfection of egg colleting tray can reduce the risk of contamination ${ }^{[36]}$.

\section{CONCLUSION}

The present study focused on the identification of Salmonella spp. in 72 samples from different farm level of Chittagong and Noakhali districts of Bangladesh. The overall prevalence of egg inner content contamination is $38.8 \%$. The egg is considered as ideal food and major source of protein in Bangladesh. But the contamination of Salmonella spp. can causes major public health burden by consuming raw or under cooked eggs and egg products. In addition, the contamination of egg by salmonella involves major health expenses in developing country. So it is necessary to monitor the infection level in marketing channel of egg and egg products

\section{REFERENCES}

1. Vaclavik VA \& Christian EW (2014). Eggs and Egg Products. Essentials of Food Science.Springer New York. pp. 173-199

2. Hasan MN, Ara N, Mamun SA, Rahman MM, Rahman MH (2009). Prevalence of Salmonella spp. in chicken egg from Khulna city. Journal of Innovation and Development Strategy. 3(3): 1-6.

3. Kassis NM, Beamer SK, Matak KE, Tou JC, Jaczynski J (2010). Nutritional composition of novel nutraceutical egg products developed with omega-3-rich oils. LWT-Food Science and Technology. 43(8): 1204-1212.

4. Gras L, Enserink R, Friesema I, Heck M., van Duynhoven Y, van Pelt W (2014). Risk Factors for Human Salmonellosis Originating from Pigs, Cattle, Broiler Chickens and Egg Laying Hens: A Combined Case-Control and Source Attribution Analysis. PloS one. 9(2): e87933.

5. Dhama K, Rajagunalan S, Chakraborty S, Verma AK, Kumar A, Tiwari R., Kapoor S (2013). Food-borne Pathogens of Animal Origin-Diagnosis, Prevention and Control and Their Zoonotic Significance: A Review. Pak J Biol Sci. 16(20): 1076-1085

6. Frenzen PD, Riggs TL, Buzby JC, Breuer T, Roberts T, Voetsch D, Reddy S (1999). Salmonella cost estimate updated using FoodNetdata. Food Review.

7. Herikstad H, Motarjemi Y, Tauxe RV (2002). Salmonella surveillance: a global survey of public health serotyping. Epidemiology and Infection. 129(01): 1-8. 
8. Carrasco E, Morales-Rueda A, García-Gimeno RM (2012). Cross-contamination and recontamination by Salmonella in foods: A review: Food Research International.45(2): 545-556.

9. King D \& Strynadka N (2011). Crystal structure of New Delhi metallo- $\beta$-lactamase reveals molecular basis for antibiotic resistance. Protein Science. 20(9): 1484-1491.

10. Guard-Petter J (2001). The chicken, the egg and Salmonella enteritidis. Environmental microbiology. 3(7): 421-430.

11. Hope BK, Baker AR, Edel ED, Hogue AT, Schlosser WD, Whiting R, Morales RA (2002). An overview of the Salmonella enteritidis risk assessment for shell eggs and egg products. Risk Analysis. 22(2): 203-218.

12. Safaei HG, Jalali M, Hosseini A, Narimani T, Sharifzadeh A, Raheimi E (2011). The prevalence of bacterial contamination of table eggs from retails markets by Salmonella spp., Listeria monocytogenes, Campylobacter jejuni and Escherichia coli in Shahrekord, Iran. Jundishapur J Microbiol. 4(4): 249-253.

13. Merchant IA and Packer RA (1969). Veterinary Bacteriology and Virology. 7th edn., The Iowa State University Press, Ames, Iowa, USA. 211305.

14. Steinfeld H, Wassenaar T, Jutzi S (2006). Livestock production systems in developing countries: status, drivers, trends. Rev. sci. tech. Off. int. Epiz. 25(2): 505-516.

15. Newell DG, Koopmans M, Verhoef L, Duizer E, Aidara-Kane A, Sprong H, Kruse H (2010). Food-borne diseases - the challenges of 20years ago still persist while new ones continue to emerge. International journal of food microbiology. 139: S3-S15.

16. Braden CR. (2006). Salmonella enterica serotype Enteritidis and eggs: a national epidemic in the United States. Clin Infect Dis. 43(4): 512-517.

17. Singh S, Yadav AS, Singh SM., Bharti P (2010). Prevalence of Salmonella in chicken eggs collected from poultry farms and marketing channels and their antimicrobial resistance. Food Res Int. 43(8): 2027-2030.

18. Perales and Audicana (1989). The role of hens' eggs in outbreaks of salmonellosis in north Spain. Int J Food Microbiol. 8(2): 175-180

19. Little CL, Surman-Lee S, Greenwood M, Bolton FJ, Elson R, Mitchell RT, O'Brien S (2007). Public health investigations of Salmonella Enteritidis in catering raw shell eggs, 2002-2004. Lett Appl Microbiol. 44(6): 595-601.

20. Little CL, Rhoades JR, Hucklesby L, Greenwood M, Surman-Lee S, Bolton FJ, Chan CH (2008). Survey of Salmonella contamination of raw shell eggs used in food service premises in the United Kingdom, 2005 through 2006. J Food Prot. 71(1): 19-26.
21. Elson R, Little CL, Mitchell RT (2005). Salmonella and raw shell eggs: results of a cross-sectional study of contamination rates and egg safety practices in the United Kingdom catering sector in 2003. J Food Prot. 68(2): 256-264.

22. Musgrove MT, Jones DR, Northcutt JK, Cox NA, Harrison MA, Fedorka-Cray PJ, Ladely SR. (2006). Antimicrobial resistance in Salmonella and Escherichia coli isolated from commercial shell eggs. Poultry science. 85(9): 1665-1669.

23. Ohtsuka K, Yanagawa K, Takatori K, HaraKudo Y (2005). Detection of Salmonella enterica in naturally contaminated liquid eggs by loop-mediated isothermal amplification, and characterization of Salmonella isolates. Appl. Environ. Microbiol. 71(11): 6730-6735.

24. Chemaly M, Huneau-Salaün A, Labbe A, Houdayer C, Petetin I, Fravalo P (2009). Isolation of Salmonella enterica in laying-hen flocks and assessment of eggshell contamination in France. J Food Prot. 72(10): 2071-2077.

25. Suresh T, Hatha AAM, Sreenivasan D, Sangeetha N, Lashmanaperumalsamy P (2006). Prevalence and antimicrobial resistance of Salmonella enteritidis and other Salmonella s in the eggs and egg-storing trays from retails markets of Coimbatore, South India. Food microbiology. 23(3): 294-299.

26. Murchie L, Xia B, Madden RH, Whyte P, Kelly L (2008). Qualitative exposure assessment for Salmonella spp. in shell eggs produced on the island of Ireland. Int J Food Microbiol. 125(3): 308-319.

27. Namata H, Welby S, Aerts M, Faes C, Abrahantes JC, Imberechts $\mathrm{H}$, Mintiens $\mathrm{K}$ (2009). Identification of risk factors for the prevalence and persistence ofSalmonellain Belgian broiler chicken flocks. Prev Vet Med. 90(3): 211-222.

28. Gould D, Kraa E, Dalton CB, Givney R, Gregory J, Stafford RJ, Kirk MD (2004). Foodborne disease outbreaks in Australia, 1995 to 2000. Commun Dis Intell Q Rep. 28(2): 211.

29. García C, Soriano JM, Benítez V, CataláGregori P (2011). Assessment of Salmonella spp. in feces, cloacal swabs, and eggs (eggshell and content separately) from a laying hen farm. Poultry science. 90(7): 1581-1585.

30. Shahzad A, Mahmood MS, Hussain I, Siddique F, Abbas RZ (2012). Prevalence of Salmonella species in hen eggs and egg storing-trays collected from poultry farms and marketing outlets of Faisalabad, Pakistan. Pak J AgricSci. 49: 565-568.

31. Chen J, Zhang L, Paoli GC, Shi C, Tu SI, Shi X (2010). A real-time PCR method for the detection of Salmonella enteric from food using a target sequence identified by comparative genomic analysis.. Int J Food Microbiol. 137(2): 168-174. 
32. Barua H, Biswas PK., Olsen KE, Christensen, JP (2012). Prevalence and characterization of motile Salmonella in commercial layer poultry farms in Bangladesh. PloS one. 7(4): e35914.

33. Vandeplas S, Dubois Dauphin R., Beckers Y, Thonart P, Thewis A (2010). Salmonella in chicken: current and developing strategies to reduce contamination at farm level. J Food Prot. 73(4): 774-785.

34. Berriman AD, Clancy D, Clough HE, Armstrong D, Christley RM. (2013). Effectiveness of Simulated Interventions in Reducing the Estimated Prevalence of
Salmonella in UK Pig Herds. PloS one. 8(6): e66054.

35. Holt PS, Davies RH, Dewulf J, Gast RK, Huwe JK, Jones DR, Willian KR (2011). The impact of different housing systems on egg safety and quality. Poultry science. 90(1): 251262.

36. Utrarachkij F, Pornraungwong S, Siripanichgon K, Nakajima C, Suzuki Y, Suthienkul O (2012).Possible horizontal transmission ofSalmonella via reusable egg trays in Thailand. Int J Food Microbiol. 154(1): 73-78. 